Running head: Novelty processing in AD

\title{
Novelty processing and memory impairment in Alzheimer's disease: a review
}

Christine Bastin $^{\text {a1 }}$, Emma Delhaye ${ }^{\mathrm{a} 1}$, Christopher Moulin $^{\mathrm{b} 2} \&$ Emmanuel Barbeau ${ }^{\mathrm{c} 2}$ a. GIGA-CRC in vivo imaging, Liège University, Allée du 6 Août, B30, 4000 Liège, Belgium. Emails: Christine.Bastin@uliege.be; Emma.Delhaye@uliege.be

b. Psychology and Neurocognition Laboratory, CNRS UMR 5105, Université Grenoble Alpes, Bâtiment Sciences de l'Homme et Mathématiques, 1251 avenue Centrale, Domaine Universitaire de St Martin d'Hères, 38040 Grenoble, France. Email: chris.moulin@mac.com

c. Centre de recherche Cerveau et Cognition, UPS-CNRS UMR 5549, CHU Purpan, Pavillon Baudot, 31059 Toulouse cedex 9, France. Email:

Emmanuel.BARBEAU@cnrs.fr

$1 \&$ 2: Equal contribution

* Corresponding author: Christine Bastin, GIGA-Cyclotron Research Centre-in vivo imaging, Liège University, Allée du 6 Août, B30, 4000 Liège, Belgium, Telephone: +32 43662369 , Fax: +32 436629 46, Email: Christine.Bastin@uliege.be 


\begin{abstract}
The detection and processing of novelty plays a critical role in memory function. Despite this, relatively little is known about how novelty influences memory in Alzheimer's disease (AD). This review sought to address whether AD patients are still sensitive to novelty; whether novelty triggers memory processes as is observed in healthy subjects; and whether it is possible to promote novelty to enhance memory at the different stages of AD. The studies reviewed showed that novelty processing is mostly impaired in AD patients, whereas it can be preserved under some conditions in MCI, particularly when cognitive demands are otherwise low. We further identify outstanding questions that should be addressed in the near future in order to more robustly establish the fate of novelty processing and detection in the course of AD. Doing so would allow to improve current models of memory impairment in AD, leading to a more comprehensive view of the sources of memory decline and could lead to neuropsychological and/or pharmaceutical rehabilitation programs.
\end{abstract}

Keywords: Alzheimer's disease, memory, novelty detection, hippocampus 


\section{Novelty processing and memory impairment in Alzheimer's disease: a review}

\section{Introduction}

Novelty processing is a fundamental cognitive ability governing a wide range of behaviours including curiosity, motivation, attention and memorization. It is particularly important for learning (Tulving and Kroll, 1995); by definition, learning concerns novel facts and situations. An efficient memory intrinsically relies on an interplay between what is detected to be novel and what is known to be familiar (van Kesteren et al., 2012).

In Alzheimer's disease (AD), many studies have been devoted to the study of memory. Intriguingly however, very little work has been carried out on how patients with AD process novelty, and virtually none regarding how novelty processing relates to their memory impairment. This is a critical oversight since impaired novelty processing could add to accounts of the severe memory impairment observed in AD. Otherwise, manipulating novelty at encoding could potentially be an effective cognitive technique to facilitate learning in patients suffering from $\mathrm{AD}$, especially in the predementia stage of Mild Cognitive Impairment (MCI, Albert et al., 2011). Thus, a better understanding of novelty processing in AD could open up new avenues for rehabilitation programs.

In this review article, we first succinctly describe what novelty is and how it is a critical component of the memory system. Following this, we review whether novelty is preserved or impaired in the course of $\mathrm{AD}$. We then summarize outstanding questions in the field that ought to be investigated in the near future and end up with a novel model of the memory impairment observed in $\mathrm{AD}$. We focus throughout this review along three main questions which are to our knowledge currently entirely unresolved: do patients with AD or MCI still detect novelty? Does novelty detection improve memory as is usually the case in healthy subjects? Is it possible to use novelty to enhance memory in AD? Our emphasis is that 
a better understanding of novelty processing in the course of $\mathrm{AD}$ is a milestone to a more complete apprehension of the nature of memory impairment in this population.

\section{What is novelty?}

\subsection{Definition}

Detection and processing of novel information can take different forms depending on the particular case in which it occurs (see Table 1 for definitions). Previous articles have differentiated novelty from deviance and surprise (e.g. Schomaker and Meeter, 2015) and we briefly differentiate these concepts in Table 1 . The most frequently studied forms of novelty are stimulus — contextual— and associative novelty.

\subsubsection{Stimulus novelty}

Stimulus novelty refers to stimuli that have never been experienced before (Kumaran and Maguire, 2007b), such as new individual objects, fractals or objects that are difficult to categorize (Schomaker and Meeter, 2015). Such events typically elicit an orienting response of attentional resources towards novel information (Corbetta and Shulman, 2002). When a stimulus is repeated, this induces behavioural and neural changes (Ranganath and Rainer, 2003). Behavioural repetition-induced changes are visible through priming effects, corresponding to faster and more efficient processing of repeated stimuli compared with novel ones. Moreover, cortical and subcortical neural activity is reduced when stimuli are repeated (i.e. repetition suppression effect, Grill-Spector et al., 2006; Nyberg, 2005; Ranganath and Rainer, 2003).

Novelty is thought to elicit a learning signal such that the novelty of a stimulus promotes learning (Tulving and Kroll, 1995). Consistently, novelty has been shown to 
enhance subsequent memory compared to stimuli that were previously familiarized (see for example the Von Restorff effect described below).

\subsubsection{Contextual novelty}

Contextual novelty represents the novelty of a familiar stimulus that is unexpected given the context in which it occurs (Kumaran and Maguire, 2007b; Nyberg, 2005; Ranganath and Rainer, 2003), for instance because it differs from other stimuli shown in the context (Schomaker and Meeter, 2015). Some authors propose that distinctiveness (i.e., when stimuli stand out from others in a series) is linked to contextual novelty (Poppenk et al., 2010a; Tulving and Rosenbaum, 2006). Another related phenomenon is deviance; a stimulus belonging to an infrequent category that is dissimilar from the category of other stimuli (Schomaker and Meeter, 2015).

Contextually novel or distinct events tend to be encoded more efficiently than less novel ones or items that do not stand out (Ranganath and Rainer, 2003; Tulving and Rosenbaum, 2006). Contextual novelty also contributes to the 'primacy effect' described in the memory literature, where items that are presented first in a study list are better remembered than items that are presented later in the list. According to Davelaar (2013), the first two or three items of a list are distinctive due to increase in the change within a distributed episodic context representation, thereby creating contextual novelty.

\subsubsection{Associative novelty}

Associative novelty occurs when the combination or configuration of two or several familiar stimuli is novel (Nyberg, 2005). Kumaran and Maguire (2007b) defined three types of associative novelty. In spatial novelty, familiar items appear in a new spatial location. In temporal or sequence novelty, familiar items are presented in a new temporal order. Finally, 
in "item-item" novelty, familiar items appear together in a new combination (e.g., recombinations in an associative recognition memory task, consisting of two previously studied items that initially appeared in different pairings).

\subsubsection{Other types of novelty}

Schomaker and Meeter (2015) defined additional types of novelty. Notably, spatial/environmental novelty refers to the novelty of an environment rather than of a stimulus, and surprise/unexpectedness refers to events that violate expectancies, due to deviations from explicit predictions (e.g., unpredicted action effects) (see also Henson and Gagnepain, 2010). Although the concept of surprise - together with the one of deviance - is readily dissociable from novelty, they tend to be confounded in the experimental assessment of novelty, so that it is not clear which aspect - novelty, deviance, or surprise - actually elicits neural responses usually ascribed to novelty (Schomaker and Meeter, 2015).

\subsection{Assessment methods}

Several experimental paradigms are commonly used to assess either novelty detection or the influence of novelty on memory.

\subsubsection{Stimulus novelty detection}

\section{Visual paired comparison task}

The amount of time spent looking at a stimulus, the number of fixations as well as a quantification of exploratory eye movements are all influenced by the detection of novelty and are thought to represent the allocation of attentional resources towards novelty and exploration of novel information (Daffner et al., 1992, 1994, 2001, 2007; Yeung et al., 2017). A common paradigm, the visual paired comparison task, consists of assessing how much time 
is spent on a novel stimulus when it is presented simultaneously with a familiar one. Usually, a longer fixation time is found for the novel stimulus. Pupil constriction has also been shown to accompany novelty detection (Kafkas and Montaldi, 2015; Vo et al., 2008) and to predict successful memory for novel stimuli (Naber et al., 2013).

\subsubsection{Contextual novelty detection}

\section{Oddball paradigm}

The detection of contextual novelty can be assessed using the oddball paradigm (see Figure 1). In this paradigm, subjects perform a target detection task in which $60 \%$ to $80 \%$ of the trials are repeated standard stimuli, $10 \%$ to $20 \%$ are infrequent to-be-detected targets (the 'oddballs'), and $10 \%$ to $20 \%$ are infrequent distracters, presented in a random sequence. Participants usually have to detect the oddball stimuli as quickly as possible. This paradigm typically induces an orienting attentional response towards contextually novel stimuli. It can be seen in the associated event-related potentials (ERPs): oddballs correctly detected generate a parietal-maximum P300 (P3b), while infrequent non-target stimuli requiring no behavioural response elicit a fronto-central P300 (P3a) (for a review see Polich, 2007; Yamazaki et al., 2001).

\subsubsection{Novelty-related memory effects}

\section{Von Restorff paradigm}

In the von Restorff paradigm, one deviant or distinctive item (so-called "the isolate") is studied among a group of relatively homogeneous items (the distinction can be made along any dimension such as size, font, colour, emotional content, or semantic category) (Hunt, 1995; Nyberg, 2005; Vitali et al., 2006). The paradigm assesses the impact of contextual novelty on memory for the contextually novel items as compared to memory for non- 
distinctive items (Von Restorff, 1933) (see Figure 1). The isolates are usually better recalled or recognized than control stimuli. Currently, the preferred explanations for this effect are the distinctiveness hypothesis according to which the isolate stands out against the similarity of other items (Hunt, 2013) and the retrieval cue hypothesis that assumes that the isolate is more easily retrieved because retrieval cue specifies only a single target contrary to control items that are all candidate targets, thus leading to more interference (Nairne, 2006).

\section{Novelty system activation}

Novelty is thought to activate a cascade of neural processes, including activation of the dopaminergic system (see below), facilitating encoding, that lasts up to 10 minutes after the novel information has been presented. New paradigms have been developed on this idea that exposure to novelty facilitates new learning. These paradigms generally expose participants to novelty, then have them study new information. Such paradigms have been shown to improve subsequent memory for information learnt after an exposure to novelty compared with performance after exposure to familiar information (e.g., Fenker et al., 2008; Schomaker et al., 2014).

\section{Pre-experimental familiarity vs novelty effect}

The impact of novelty on memory encoding and retrieval can be otherwise assessed by manipulating pre-exposure versus novelty of the stimuli to be encoded in a memory task (Aberg and Nilsson, 2001, 2003; Kormi-Nouri et al., 2005; Tulving and Kroll, 1995). Typically, in such paradigms, recognition of novel words is contrasted with recognition of words that have been familiarized through repetition before the actual encoding phase (Tulving and Kroll, 1995). Variants of this procedure exist with various types of materials such as proverbs (Poppenk et al., 2010a). 


\subsection{Cognitive models of novelty processing and memory}

Several models have been proposed to account for the computations triggering novelty signals, depending on the type of novelty.

\subsubsection{Stimulus novelty}

Some models assimilate novelty detection with familiarity detection (i.e. familiarity-based recognition memory), in such a way that familiarity and novelty detection processes can be considered as two ends of a single continuum drawing on the same cognitive mechanism (Brown and Bashir, 2002; Fernandez and Tendolkar, 2006; Grill-Spector et al., 2006; Horner et al., 2012). These models propose a rapid novelty/familiarity discrimination system and are based on the notion of repetition priming and repetition suppression at a neural level.

Alternatively, Kafkas and Montaldi $(2014,2015)$ posit a 'dual-route with convergence' recognition memory mechanism in which novelty and familiarity produce distinct signals that stem from distinct processing pathways, that subsequently converge to produce a unitary relative-familiarity signal behaving as expected from a familiarity-novelty continuum despite distinct upstream processing paths. In support, an fMRI study showed familiarity and novelty in distinct brain regions in an initial phase, with subsequent common neural bases processing familiarity and novelty as one unitary mechanism (Kafkas and Montaldi, 2014).

\subsubsection{Contextual novelty}

In the case of contextual novelty, some models proposed that it relies on a comparator mechanism between prior expectations and experience (also named match-mismatch models (Kumaran and Maguire, 2007a, 2009)) to explain the computation of novelty signals (see also 
Henson and Gagnepain, 2010; Lisman and Grace, 2005; Ratcliff, 1978). These models generally consider that a given input is compared to stored memories. Recognition (or familiarity) happens as soon as the input item finds a match in stored representations. Novelty detection will only be triggered once the entire store of representations has been looked over without finding any corresponding match. This implies waiting until the slowest comparisons terminate to take a novelty decision. Importantly, these models predict that the mechanism of novelty detection is distinct from and slower than the mechanism of familiarity. This class of models, as well as the familiarity/novelty discrimination system and the 'dual-route with convergence' model are schematized in Figure 2. None of these models receives unanimous support, and only a few experiments have directly compared familiarity to novelty detection (e.g., Delhaye et al., 2017).

It seems important to note that novelty detection and processing are moreover modulated by a series of cognitive processes such as for instance phasic alertness that allow one to orient one's attention towards novel stimuli. Thus, the integrity of such processes are a prerequisite for efficient novelty processing.

\subsection{Neural bases of novelty}

The detection of novelty and novelty-related memory effects rely on a large-scale cerebral network, in which the hippocampus and other temporal lobe structures, the prefrontal cortex and the substantia nigra/ventral tegmental area play a crucial role (Ranganath and Rainer, 2003). Neuropsychological studies have pointed to the need for intact hippocampal structures and the prefrontal cortex in order to be able to process novelty. More precisely, there is functional specialization within the MTL, with some regions being more sensitive to certain kinds of novelty. The middle hippocampus would react to associative novelty, whereas the 
perirhinal cortex is specifically activated by stimulus novelty (Kohler et al., 2005) or lack of familiarity (Kafkas and Montaldi, 2018). The amygdala was also found to respond to novel unusual stimuli (Blackford et al., 2010).

\subsubsection{Stimulus novelty detection}

Hippocampal lesions were shown to disrupt the preference for novelty in visual paired comparison tasks (Munoz et al., 2011; Pascalis et al., 2004). Moreover, focal lesions to the prefrontal cortex impair the ability to detect the novelty of a stimulus in a memory task (Bastin et al., 2006; Schacter et al., 1996) and disrupt attention towards novel events, as demonstrated by reduced viewing time for novel items compared to controls and diminished P3 amplitude (Daffner et al., 2000a, 2000b). Neuronal recordings also indicate neurons responding specifically to novel stimuli in the perirhinal cortex. These neurons have relatively short latencies and are intermixed in the perirhinal cortex with other neurons coding for familiarity and recency (Xiang and Brown, 1998). Neurons coding for novelty (and familiarity) have also been identified in the human hippocampus (Rutishauser et al., 2006).

\subsubsection{Contextual novelty detection}

The hippocampus shows robust, large, ERPs specifically induced by target stimuli during oddball paradigms (Halgren et al., 1980; McCarthy et al., 1989) (Figure 3). The source of these ERPs is more precisely thought to originate from the CA1 region (Barbeau et al., 2017; Brankack and Buzsaki, 1986). Interestingly, these ERPs are induced only when participants specifically pay attention to the out-of-context target (endogenous attention) (Barbeau et al., 2017), indicating that the hippocampus is involved in novelty when it is processed explicitly. The activation of the hippocampus during oddball tasks is also shown using fMRI, with visual and auditory stimuli (Crottaz-Herbette et al., 2005). In contrast, the perirhinal cortex does not 
present any specific activity during oddball tasks, demonstrating that the hippocampus plays a special role with regard to the processes at play during oddball tasks. Oddball tasks also induce novelty responses in many other brain areas as shown by intracranial recordings in the human (Halgren et al., 1998) and fMRI (Yamaguchi et al., 2004). Notably, a change in a series of sensory stimulation elicits activation of a network involving the temporoparietal junction, inferior frontal gyrus, insula, cingulate and supplementary motor areas (Downar et al., 2000), reflecting an attention orienting response (Corbetta and Shulman, 2002). In addition, stimulus novelty, associative novelty and environmental novelty activate the substantia nigra/ventral tegmental area (Bunzeck and Duzel, 2006; Fenker et al., 2008; Schott et al., 2004), a key region for dopaminergic neuromodulation.

\subsubsection{Novelty-related memory effect}

With regard to the novelty-related memory effect, a central role seems again to be played by the medial temporal lobe (MTL). Notably, neuropsychological studies have shown that hippocampal lesions reduce the novelty-related memory benefit (Kishiyama et al., 2004). Novelty triggers a response in the anterior part of the hippocampus, which decreases with repetition (Kumaran and Maguire, 2006, 2007a; Strange and Dolan, 2001; Strange et al., 2005). Additionally, the MTL is consistently activated when participants process novel stimuli in memory tasks, both at encoding (Habib et al., 2003; Kirchhoff et al., 2000; Poppenk et al., 2010b; Stern et al., 1996) and at retrieval (de Chastelaine et al., 2017; Kafkas and Montaldi, 2015; Poppenk et al., 2008; Tulving et al., 1996). Moreover, the specific MTL regions that react to novelty appear to differ from the MTL regions supporting recollection and familiarity in some studies (Daselaar et al., 2006).

Activation of the ventrolateral prefrontal cortex and lateral temporal cortex during encoding of novel items predict subsequent memory for these items (Fenker et al., 2008; 
Kirchhoff et al., 2000; Poppenk et al., 2010b; Reggev et al., 2016), suggesting that these regions contribute to efficient encoding of novel items. However, because they also predict subsequent memory when contextual novelty is held constant (Kirchhoff et al., 2000), this likely reflects the role of these regions in encoding in general (Badre and Wagner, 2002; Thompson-Schill et al., 1997). Moreover, the occurrence of an unexpected novel item during a recognition memory task activates the substantia nigra/ventral tegmental area, and enhances functional connectivity between this region and the hippocampus (Kafkas and Montaldi, 2015), indicating an interplay between the hippocampus and the dopaminergic system.

\subsection{Neurobiological models of novelty processing}

An important neurobiological model relating novelty and memory has been put forward by Lisman and Grace (see also Duzel et al., 2010; Lisman and Grace, 2005) (Figure 4). The authors suggest that a loop between the hippocampus and the ventral tegmental area (VTA) facilitates encoding of new information. The general idea behind that model is that the CA1 region of the hippocampus compares predictions made through the tri-synaptic and CA3 pathway to the hippocampus and sensory reality arriving to CA1 through the monosynaptic direct pathway. In the case of a novel event, a novelty signal activates the VTA through the accumbens nucleus and ventral pallidum. The VTA in turn activates dopamine release in CA1 facilitating late long-term potentiation (LTP). Finally, entry of novel information into long term memory is regulated as a function of goal-related motivation and salience information (i.e., whether the object is behaviourally relevant), and this function is provided by the prefrontal cortex and limbic areas, so that the memory system only encodes important novel information. This model has been subsequently refined (Lisman et al., 2011; Otmakhova et al., 2013) and is supported by fMRI activation studies which have related the activation of the dopaminergic system with better memory (Wittmann et al., 2005, 2007). In a recent study in 
human patients, Kaminski et al. (2018) recorded the activity of individual neurons in the substantia nigra and identified dopaminergic neurons that were sensitive to the novelty of stimuli. According to Kafkas and Montaldi (2018), this hippocampal-VTA dopaminergic loop specifically supports the detection and encoding of contextually novel stimuli. In contrast, stimulus novelty triggers directly acetylcholine-mediated encoding in the hippocampus.

\section{Novelty in Alzheimer's disease: impaired or preserved?}

\subsection{Physiopathology of Alzheimer's disease}

$\mathrm{AD}$ is the most common form of brain pathology leading to cognitive impairment in the adult, affecting as many as 8 percent of the population around 70 years of age (World Health Organization). It is a complex neuropathological disease characterized by the accumulation of beta-amyloid and abnormally phosphorylated tau proteins in the brain (Selkoe and Hardy, 2016). These lead to a cascade of synaptic and LTP changes, neuronal death and a variety of cognitive impairments taking place over the course of several decades (Braak et al., 2011; Jack et al., 2013; Sutphen et al., 2015). Consequently, several stages have been identified, including a preclinical, asymptomatic stage (characterized by the presence of biomarkers indicating amyloidosis in the brain using PET or CSF analyses in cognitively healthy individuals), a prodromal stage (early, symptomatic, predementia stage of $\mathrm{AD}$, characterized by MCI) and a dementia stage (Dubois et al., 2010).

Amyloidosis appears to diffuse in the brain from the onset of the disease and may impact memory networks early-on (Sperling et al., 2014). Neurofibrillary tangles occur first in more circumscribed regions, such as in the brainstem and in MTL structures, most notably, in the entorhinal and perirhinal cortices before reaching the hippocampus (Braak and Braak, 1995; Braak et al., 2011). Changes in MTL structures involve neuronal death, atrophy of subhippocampal and hippocampal structures and progressive memory decline at the onset of 
the prodromal stage (Dubois et al., 2014). More specifically, dysfunctional familiarity-based memory has been associated with volume loss in the perirhinal cortex in MCI, whereas recollection deficits have been related to hippocampal atrophy (Westerberg et al., 2013; Wolk et al., 2011). Subsequently neuropathological changes slowly spread to other cortical areas in the temporal and frontal lobes.

Because the different structures of the MTL all appear to play a role in novelty and because these structures are impaired early in the course of $\mathrm{AD}$, it would be expected that novelty responses will be reduced compared to those of healthy subjects. These changes may differ however depending on the stage of the disease. For this reason, we provide in the following sections the MMSE (Mini-Mental State Examination; Folstein et al., 1975) of the groups of patients whenever available.

\subsection{Dopamine in $A D$}

Although it may have gone long unnoticed, the dopamine system may be disrupted early in AD. In a review, Martorana and Koch (2014) concluded that dopamine levels are associated with cognitive impairment in $\mathrm{AD}$, although the pathogenic mechanisms leading to dysfunction of the dopaminergic system and the time course across the disease need to be clarified. Nobili et al. (2017) identified dopaminergic neuronal loss specifically in the VTA in a mouse model of $\mathrm{AD}$ at the pre-plaque stage, therefore at a relatively early stage of the disease. The progression of VTA dopaminergic neuronal death correlated furthermore with hippocampal plasticity impairment and decreased memory performance.

It follows that increasing dopamine levels in patients with AD could possibly restore memory functions. This hypothesis was tested by Koch et al. (2014) who administered rotigotine, a dopamine agonist, to AD patients (MMSE ranging from 18 to 24). Although the patients showed impaired cortical LTP-like activation at baseline as assessed by intermittent 
theta burst stimulation, this LTP-like level was restored and normalized after rotigotine administration, further supporting a role of dopamine in $\mathrm{AD}$, most notably in relation to LTP plasticity. Moreover, the restoration of dopaminergic transmission has been demonstrated to play a role in memory and learning in a mouse model of AD (Ambree et al., 2009; GuzmánRamos et al., 2012).

Overall, dopamine levels may be decreased in AD and this may affect the hippocampus and memory. These findings further suggest that novelty, which triggers dopamine-related LTP in the hippocampus in the healthy brain, could be dysfunctional in AD. AD entails neurobiological changes affecting different parts of the neural system supposed to support novelty processing. Consequently, one should observe reduced novelty responses in AD patients already at the prodromal stage. We will now review the extant data relative to novelty processing in $\mathrm{AD}$ and $\mathrm{MCI}$.

\subsection{Electrophysiological responses to novelty in $A D$}

Using an oddball paradigm thought to reflect contextual novelty detection, Daffner et al. (2001) showed the amplitude of the novelty P3 to be smaller in AD patients (MMSE: mean = 24, SEM = 1) compared with healthy older adults. Accordingly, Lee et al. (2013) also showed decreases in the amplitude of the novelty P3, which appeared to be correlated with the deterioration of language, memory and executive function observed in AD patients (MMSE, $16.1 \pm 5.2$ ). A recent meta-analysis (20 studies, 646 subjects, mean MMSE per study ranging from 16.2 to 24.0; median: 20.2) performed by Hedges et al. (2016) confirmed reduced P3 amplitude in patients with mild AD. This finding was corroborated in another meta-analysis that found increased P3 latency in patients with mild AD (Howe et al., 2014). Interestingly, this study also included a subanalysis of 8 studies focusing on patients with MCI. The latency of the P3 was also found to be increased in this group, although with a smaller effect size than 
in the mild AD group (0.78 vs. 0.99), suggesting a progressive impact of the disease on novelty as indexed by the P3. Electrophysiological responses to novelty thus appear to progressively change during the course of AD.

\subsection{Neuroimaging correlates of novelty in $A D$}

A few fMRI studies have examined cerebral activations during the encoding of novel stimuli compared to the encoding of repeated stimuli.

\subsubsection{Stimulus novelty}

In one study in mild to moderate AD patients, Golby et al. (2005; see also Rombouts et al., 2000) reported less MTL activation in response to novel scenes (MMSE: 18-23, mean 20.8) compared with controls. Moreover, smaller MTL novelty responses correlated with poorer subsequent explicit memory for the novel scenes.

\subsubsection{Associative novelty}

Whereas healthy older participants activated the hippocampus and entorhinal cortex for novel face-name pairs more than for repeated face-name pairs, mild to moderate AD patients (mean MMSE: $21 \pm 3$ ) showed significantly reduced novelty-related hippocampal and entorhinal activity (Dickerson et al., 2005; Sperling et al., 2003). Another study (Pihlajamaki et al., 2011) focused on the repetition suppression response in the hippocampus when novel facename pairs are repeated. It showed that, in a group mixing mild AD patients (MMSE: $23 \pm 4$ ), MCI patients $(\mathrm{CDR}=0.5$, MMSE: $29 \pm 1)$ and healthy controls, reduced repetition suppression was related to subsequently poorer memory for the novel pairs. In MCI patients, Dickerson et al. (2005) reported hyperactivation of the hippocampus during encoding of novel face-name pairs. Subsequent work exploring this hyperactivation suggests that it arises 
because of a synaptic dysfunction within the hippocampus (Miller et al., 2008; O'Brien et al., 2010; Putcha et al., 2011).

Altogether, fMRI data suggest that the MTL responses to novelty are altered in both MCI and AD patients and that this disrupted novelty response is linked with poorer subsequent memory for novel stimuli.

\subsection{Behavioural correlates of novelty in $A D$}

An important question is whether patients with $\mathrm{AD}$ show behavioural differences compared to healthy subjects when they are required to engage in novelty processing. Overall, there has been very few direct investigations of the ability of $\mathrm{AD}$ patients to detect novelty and/or to benefit from the impact of novelty on memory to our knowledge (see Table 2 for main findings). We present first results on $\mathrm{AD}$ at the dementia stage and then results at earlier stages of the disease.

\subsubsection{Detection of novelty in $A D$}

\section{Stimulus novelty}

A small number of studies examined the extent to which AD patients' attention is attracted to novel stimuli by measuring the time spent to view stimuli. In general, visual search times are longer in $\mathrm{AD}$, and patients show clear qualitative differences on top-down perceptual tasks compared to controls (for a review, see Molitor et al., 2015). Using eyetracking to measure viewing time in a visual paired comparison task, Daffner and colleagues (Daffner et al., 1992, 1999) showed that AD patients spent less time looking at novel incongruous stimuli than healthy older participants, and that they distributed their viewing time equally between the familiar and the novel incongruous stimuli. This reduced attention to novel items was not explained by dementia severity. Daffner et al. (1999) observed some variability among the 
AD group, with some patients showing a residual attraction to novel stimuli, whereas others showed no sign of attention to novelty. These two subgroups did not differ in the ability to explicitly report stimuli as novel. The only difference between these subgroups was that the patients who were indifferent to novelty were judged as more apathetic in everyday life by their informants than the patients with residual attention to novelty. A further study by Chau et al. (2015) measured mild to moderate AD patients' novelty preference (MMSE: $22.2 \pm 4.0$ ) using eyetracking in a visual paired comparison paradigm. They showed that patients spent more time viewing the familiar than the novel pictures compared with controls, and shorter fixation times for novel pictures were associated with lower score on the MMSE (Chau et al., 2015) as well as steeper cognitive decline in subsequent years (Chau et al., 2017).

\section{Contextual novelty}

Using an oddball paradigm, Daffner et al. (2001) examined ERPs associated with the processing of repeated and novel line drawings in healthy older adults and mild AD patients (MMSE: $24 \pm$ 1). Participants decided how long they viewed each picture. Similar to eyetracking data, $\mathrm{AD}$ patients did not spend more time looking at novel stimuli than familiar ones, contrary to controls. Moreover, in the AD group, the novelty P3 effect was reduced. Interestingly, the amplitude of the novelty P3 effect predicted how much time patients spent looking at novel pictures. Reduced novelty P3 amplitude was also associated with apathy in AD patients.

\subsubsection{Novelty - insights from repetition priming}

At its most basic, novelty detection in the human memory system hinges on the ability to detect whether a stimulus has been encountered before. The central aim of research into repetition priming is to examine how the nervous system responds to repeated stimuli. In 
priming studies, the explicit awareness of repetition is not the focus of study, but the facilitated processing of a stimulus seen for a second time. A crucial distinction is between repetition and conceptual priming, with differences between the two seen in Alzheimer's disease (e.g., Keane et al., 1991; Vaidya et al., 1999). Here we focus briefly on repetition priming since critically for our aims, intact repetition priming could be interpreted as related to novelty processing: something occurs differently in the cognitive system for a stimulus seen for the first time than for a repetition. In a review, Fleischman (2007) suggested that changes in priming were not part of the healthy aging process, but that when priming is impaired in older groups it points to a pathological process. However, they did not find a uniform decline in priming in Alzheimer's disease and MCI. Rather, tasks which involved identification - such as picture naming, and word naming - showed intact priming in Alzheimer's disease and MCI. It was only where production was required, such as with stemcompletion tasks, where there were differences between healthy and pathological groups.

More recently, Ober and Shenaut (2014) used a lexical decision task and showed intact repetition priming for words; people with Alzheimer's disease (MMSE range: 12-28) showed the appropriate facilitation in reaction time the second time they encountered a word. In addition, in their task, nonwords were also repeated. In such cases, a performance decrement (slowing) is expected for word-like nonwords, since being recently activated they become similar to real words (e.g., McKoon and Ratcliff, 1979). Ober and Shenaut (2014) showed this negative priming effect (i.e., novel stimuli) in their AD patients. They argue that this shows that people with $\mathrm{AD}$ are able to construct a representation of a novel stimulus which then - at least implicitly - has consequences for further processing. The slowing of processing - in healthy participants and AD alike - is an interesting one because it points to a confusion whereby a novel nonword is difficult to distinguish from a real word due to the fact that it is has been recently activated. 
The sensitivity to repetition in $\mathrm{AD}$, however, is not uniformly preserved. Evidence of preserved repetition priming effects in AD patients contrasts with fMRI data showing reduced hippocampal repetition suppression in MCI and AD patients (Pihlajamaki et al., 2011),

outlined above. In the context of repeated study-test trials in an explicit task, AD patients have been found to appropriately allocate longer time to study novel items (i.e. words presented for the first time) in comparison to items shown twice or three times (Moulin et al., 2000) - which could be taken as an appropriate sensitivity to repetition. Critically, however, explicit ratings did not discriminate between frequencies of presentation: people with $\mathrm{AD}$ allocate longer study time to encode items seen the first time, but they do not judge items seen multiple times as being any more easy to remember. On the whole, these findings suggest that AD patients may have some preserved capacity to identify novelty at an implicit level. Taken with the reduced hippocampal repetition suppression, we might propose an intact processing of repetition according to standard implicit behavioural measures, but an inappropriate processing of novel stimuli in the context of explicit memory, which we review next. In short, there is a dysfunctional neural response to repetition in the temporal lobe and a failure to be aware of repetition in an explicit memory task.

\subsubsection{Novelty and explicit memory in $A D$}

\section{Novelty-related memory effect}

Only a few studies have directly tested whether AD patients learn novel information better than familiar information. Lekeu et al. (2003) used Tulving and Kroll's (1995) paradigm to investigate recognition of familiarized versus novel words in patients with mild AD (mean MMSE: $22 \pm 4$ ) and controls. Both patients and controls showed greater recognition accuracy for novel than familiar words, which indicates a residual novelty effect in AD. Nevertheless, AD patients had poorer recognition performance, due to a higher false alarm rate for 
unstudied words in the novel condition compared with controls. This study also showed that, in patients, recognition of novel words correlated with metabolism in the right anterior hippocampus. This suggests that the capacity to take advantage of novelty to improve memory encoding is related to the integrity of the hippocampus, consistent with neurobiological models that emphasize its central role in novelty effects on memory.

Vitali et al. (2006) evaluated whether mild AD patients (MMSE range: 20-28, mean: $23 \pm 2$ ) demonstrated the von Restorff effect in a task where distinctiveness was created by presenting words in a different font size than the others. Healthy older participants recalled more distinctive words than non-distinctive words, but there was no effect in AD patients. Intriguingly, no AD patients noticed that some words had a bigger font, raising the possibility of a contribution of visuoperceptual impairment to the disappearance of the von Restorff effect. Furthermore, there was no correlation between sensitivity to novelty and overall memory performance, indicating that the absence of the novelty effect on memory was not related to the memory impairment itself. Recently, Vallet et al. (2017) also showed that mild to moderate $\mathrm{AD}$ patients (MMSE range: 18-27) did not display better memory for isolated items (a small number of pictures presented on a yellow background) compared to nonisolated items (many pictures on a white background). In light of the retrieval cue hypothesis (Nairne, 2006), it may be that AD patients failed to benefit from the reduced interference linked to the novel retrieval cue compared to control items, possibly because less control items competed at retrieval.

Other pieces of evidence relative to novelty-related memory effects in AD come from the study of serial position effects in list recall tasks. Whereas the recency effect (i.e., better recall of the last items of the list) appears preserved in $\mathrm{AD}$ (mild to moderate AD: mean MMSE, $19 \pm 5$; very mild AD: mean MMSE, $25 \pm 1$ ), the primacy effect is severely 
diminished in the patients (Bayley et al., 2000; Cunha et al., 2012). This suggests that AD patients fail to benefit from the contextual novelty of the first items of the list.

\subsubsection{Novelty detection in the early course of Alzheimer's disease}

Most studies conducted in the dementia stage of $\mathrm{AD}$, though scarce, suggest that $\mathrm{AD}$ patients fail to orient attention to novel stimuli and do not benefit from the novelty of an item to encode and remember it better than familiar items, even though some residual effect can be detected in some patients. However, as Alzheimer pathology starts decades before dementia symptoms arise, it would be of great interest to determine when novelty detection begins to be impaired. Currently, there is limited information regarding novelty detection in the predementia stages of AD.

However, in healthy aging, it seems that there is a decreased responsiveness to novelty and an altered processing of rare targets (e.g., Fabiani and Friedman, 1995). More recent evidence, in contrast, supports the idea that older participants are heterogeneous in their response to novelty and that decreased attention to novelty is not the rule during the aging process. For example, Daffner et al. $(2006 ; 2007)$ showed that older adults with high performance on attention and executive function tests spent more time looking at novel items in pairs and demonstrated a larger novelty P3 ERP effect than older adults with poorer neuropsychological performance. In the framework of the cognitive reserve hypothesis (Stern, 2009), high-performing older adults are less likely to develop dementia than low-performing older adults. Although this is speculative, Daffner et al.'s $(2006,2007)$ results could mean that a decreased response to novelty would be seen early on in individuals with higher risk of developing AD. 


\section{Stimulus novelty}

In MCI, the existing data point to relatively preserved stimulus novelty detection under some conditions, with an emergence of a decreased sensitivity to novelty when task demands increase. For instance, Crutcher et al. (2009) used the visual paired comparison paradigm in a small sample of $6 \mathrm{MCI}$ patients. By measuring viewing time with eyetracking, the authors showed that, when encoding and recognition were separated by a 2 -second delay, the MCI patients and control participants performed comparably, viewing the novel picture $71 \%$ of the time. However, when the study-test delay increased to 2 minutes, MCI patients viewed the novel picture only $53 \%$ of the time, while control participants remained above $70 \%$. This reveals that the orientation of attention to novelty diminishes in MCI when the novel status of an item must rely on long-term memory. In contrast, immediate orienting of attention to novelty, when memory load is limited, is preserved in MCI.

Yeung et al. (2013) also used eyetracking measures of the number of fixations to repeated and novel objects in a continuous passive viewing task. The novel objects were either relatively different from or very similar to previously presented ones. The populations studied were older participants at risk for AD (below cut-off MoCA score), healthy older participants and young participants. Both young participants and healthy older adults made more fixations to the two kinds of novel objects compared to studied objects. In contrast, older participants at risk for AD showed normal eyetracking behaviour towards novel stimuli that were different from studied ones, but made significantly less fixations to novel stimuli that were very similar to studied objects. In other words, these participants automatically processed these novel items as if they were familiar. These findings speak to a novelty detection impairment in individuals at risk for $\mathrm{AD}$ only when novelty is subtle and concerns very fine perceptual discrimination. 


\section{Novelty-related memory effect}

In immediate free recall tasks, MCI patients, like AD patients, have a diminished primacy effect (Howieson et al., 2011). Moreover, the impaired primacy effect predicts whether a MCI patient will develop dementia in the following years or not (Cunha et al., 2012). Therefore, the contextual novelty of the first items of the list does not help the patients to remember those items better and such difficulty may be an early sign of future AD. Furthermore, in MCI, the primacy effect in delayed recall of a word list correlated with functional connectivity between the hippocampus and several brain regions including temporal, frontal and middle cingulate cortex and the thalamus (Brueggen et al., 2016). Finally, Belleville et al. (2011) evaluated recognition memory performance of MCI patients and controls after an encoding phase where familiar items (i.e., words) and novel items (i.e., pseudowords) were presented. This task did not yield any novelty-related memory effect, as memory was better for familiar than for novel items. MCI patients showed impaired recognition memory for familiar items, accompanied by a decrease in recollection of these items, but their recognition performance for novel items did not differ from that of the controls. Although the task failed to yield a memory benefit for novelty, it nevertheless reported preserved memory for novel items in MCI.

In brief, novelty detection and novelty-related memory effects may be relatively preserved in people with MCI, except when task demands are high. Nevertheless, there is little or no evidence that the populations included in these studies are actually in a prodromal stage of $\mathrm{AD}$ based on currently used amyloid biomarkers. Therefore, currently available data cannot truly ascertain the status of novelty detection and processing in the earliest phase of AD. The only piece of evidence suggesting that impaired novelty processing could predict future dementia comes from the study by Cunha et al. (2012) on the primacy effect. 


\section{Outstanding questions}

We review here questions that need to be addressed in the near future (summary in Table 3 ).

\subsection{Identifying the patterns of impairments across different types of novelty}

Most current data suggest that patients in the dementia stage of AD fail to orient attention to novel stimuli and do not benefit from novelty during memory tasks. The different studies have however each focused on one type of novelty, and relationships with cerebral changes have rarely been explored. In order to fully establish the status of novelty detection and processing in $\mathrm{AD}$, a systematic investigation of all types of novelty within the same sample of AD patients is warranted. Related to this idea, given that stimulus-, contextual— and associative novelty rely on distinct MTL regions, one could expect that they are independently affected as a function of the stage of the disease and the extent of cerebral changes to the MTL regions in the patients. Differential progression of neurofibrillary tangles across the entorhinal cortex, perirhinal cortex and hippocampus would presumably lead to different trajectories of degradation of the different types of novelty processing. Moreover, the additional contribution of prefrontal pathology, which arises during the course of AD (Salat et al., 2001), should be considered as it might impact attentional orientation to novelty (Daffner et al., 2000b) and assessment of the importance of novel events to guide their encoding (Lisman and Grace, 2005).

\subsection{Establishing the link between novelty and memory impairment during the time course of} $A D$

An important related question is how changes to novelty detection relate to changes in declarative memory functioning, especially recollection and familiarity, along the chronological course of $\mathrm{AD}$. This may notably help to contribute to answer to the question of 
the relationship between novelty and familiarity (see section 2.3). In classical recognition memory tasks, old and new stimuli have to be discriminated. Rejection of new stimuli is sometimes taken as an index of novelty effects (stimulus novelty in single item recognition memory and associative novelty in association recognition memory), while endorsement of old items would rely on familiarity (e.g., de Chastelaine et al., 2017; Kafkas and Montaldi, 2014). In MCI and AD, higher rates of false recognition of new items (Budson et al., 2003) and of recombined pairs (Gallo et al., 2004; Genon et al., 2013; Troyer et al., 2012) could be taken as evidence of poor detection of stimulus and associative novelty, respectively. In parallel, familiarity-based recognition memory, defined by opposition to recollection, may be the first memory function to decline (Besson et al., 2015; Didic et al., 2011; Wolk et al., 2013), although this is debated (for reviews, Koen and Yonelinas, 2014; Schoemaker et al., 2014). If novelty and familiarity are the two ends of a single continuum (Brown and Bashir, 2002; Fernandez and Tendolkar, 2006; Grill-Spector et al., 2006; Horner et al., 2012), one may expect that novelty starts to decline at the same time as familiarity. In contrast, if novelty detection and familiarity are independent functions (de Chastelaine et al., 2017; Kafkas and Montaldi, 2014), one may see them change along different time courses as the pathology progresses. These hypotheses clearly require future work. One challenge will be to create tasks that allow to assess separately novelty and familiarity, as recognition memory tasks intermix both (de Chastelaine et al., 2017).

\subsection{Exploring the impact of the dopaminergic neuromodulation system on novelty and} memory in $A D$

One intriguing possibility could be that, in MCI, immediate orientation of attention by novelty is preserved, but the interaction between novelty and memory is altered (Crutcher et al., 2009). Thus, a key point that deserves further investigation is the dopaminergic 
neuromodulation system at the different stages of AD. How well does the hippocampus-VTA loop function in the preclinical, prodromal and dementia stages of AD? How does this relate to novelty effects? Such questions would need to be answered in order to fully understand behavioural novelty-related effects and their cerebral underpinnings. One way to approach these questions would be to correlate novelty effects with indirect measures of dopaminergic activation in patients, such as eye movements, which have been shown to track dopaminergic activity (Blin et al., 1990; Karson, 1983; Taylor et al., 1999). Further combining these measures with fMRI assessment of functional connectivity between the hippocampus and VTA would provide indication as to changes in the novelty-related neurobiological system as $\mathrm{AD}$ pathology progresses. If there is some residual functioning within this system, it could in principle be possible to improve novelty detection by pharmacological manipulation of dopamine in patients. A related, important, question suggested by some studies (Daffner et al., 1999 ) is whether only a subgroup of patients with AD show additional complications due to impairment to the dopaminergic system rather than all patients showing dopaminergic impairment in the course of the disease. It seems critical to study whether such a subgroup exists as it may be the target of specific clinical trials.

\subsection{Determining the clinical correlates of novelty in $A D$}

As well as links with memory and learning, there are undoubted links between novelty processing and other real-world behaviours in $\mathrm{AD}$ patients, such as apathy and personality changes. Apathy, i.e. loss of motivation, curiosity and interest/engagement in new events, is one of the most commonly experienced neuropsychiatric symptoms in $\mathrm{AD}$ (Robert et al., 2009). Daffner et al. (1999) showed that AD patients who failed to demonstrate exploratory eye-movements to novel items were rated by informants as being more apathetic than AD patients with normal visual fixation to novelty. In this context, one issue that deserves further 
investigation is whether the link between indifference to novelty, poor memory and clinical changes, such as apathy in everyday life, could indicate that common neurobiological mechanisms underlie both symptoms. Lack of visual exploration presumably underpins a number of critical real-world behaviours, including the exploration of facial emotion. Consistently, Ogrocki et al. (2000) showed that AD patients could explicitly discriminate facial emotions as effectively as controls, but their eye-movements differed, spending proportionately longer time on irrelevant areas of the face. Also indicating alteration of curiosity, there is some evidence that people with $\mathrm{AD}$ allocate less looking time to incongruous parts of an image (e.g. a horse with its hind legs missing; Daffner et al., 1992), and tend to 'overlook' unusual parts of an image (Moser et al., 1995). Although explicit measures of curiosity exist, whereby participants rate their subjective experience of desire to find out currently unknown information (e.g., Litman, 2005), there has, to our knowledge, been no attempt to take such measures in $\mathrm{AD}$.

Moreover, novelty seeking is a key factor in the personality dimension of openness, according to the 'big-five' personality schedule (Costa and McCrae, 1992). Interestingly, Robins Wahlin and Byrne (2011) pinpoint a marked reduction in openness scores in Alzheimer's disease. A measure of novelty seeking using scales such as the tridimensional personality questionnaire (Cloninger et al., 1991) could be useful to understand individual variability in the response to novelty and to identify how AD modifies such personality traits.

\subsection{Manipulating novelty to improve memory in $A D$}

Even if current studies mostly point to impaired novelty processing in $\mathrm{AD}$, the existence of residual effects in some cases opens the door to using novelty in rehabilitation programs. It remains possible that improving the novelty of a stimulus or triggering the novelty system could be beneficial in AD. Better understanding the trajectories of changes to the different 
kinds of novelty across the AD spectrum would allow us to determine how and when one can improve learning by manipulating saliency, using approaches such as the von Restorff paradigm, or by activating the novelty system (Schomaker et al., 2014). Alternatively, stimulation of the novelty neurobiological system may be achieved by pharmaceutical modulation of dopaminergic activity, as mentioned earlier. Given that novelty seems to be impaired in the dementia stage of $\mathrm{AD}$, we do not expect that it can be restored fully to the level of efficiency of healthy subjects. However, a relative benefit might be observed (e.g., increased memory for stimuli presented using a novelty paradigm compared to stimuli presented in familiar condition). In the earlier stage (prodromal AD), when novelty processing is less affected, the benefit could be even larger and lead to a strong impact on everyday life memory functioning. Studies thus need to be performed to verify if promoting novelty could enhance, at least relatively, memory in patients with $\mathrm{AD}$. This could open a new avenue into memory support programs for both clinicians and people taking care of patients with MCI and AD.

\section{A novel model of memory impairment in Alzheimer's disease}

More broadly, a possibility is that taking into account novelty might be highly beneficial to conceptualize better models of the memory impairment in AD. Although AD patients' memory difficulties are commonly directly linked to medial temporal lobe impairment in relation to tau pathology (Barbeau et al., 2012; Bastin et al., 2010, 2014; Didic et al., 2011; Genon et al., 2012), a different line of research, originating mainly from resting state neuroimaging, has emphasized the role of impaired networks with regards to amyloid pathology to account for the memory impairment observed in this disease (Nestor et al., 2006; Sperling et al., 2014). This network includes a set of medial cortical regions such as the posterior cingulate and medial prefrontal cortices. However, given our review above, it is 
timely to include novelty as another source of memory dysfunction in AD. Altogether, these three sources of impairment (summarized in Figure 5) could explain the severe memory alteration seen in AD. Such a model, by proposing an integrative vision of the memory impairment in AD could yield a more complete view of preserved and impaired capacities in the course of the disease and offer opportunities for better rehabilitation. It could also explain the heterogeneity of memory disorders observed in this disease depending on the relative impairment of each source of memory deficit (Barbeau et al., 2006). It is also likely that future work will be able to unravel the dynamics of the contribution of each source of memory impairment at different stages of the disease.

Last, but not least, this model puts forward the idea that neurotransmitters, such as dopamine in the present case, may be involved in memory dysfunction in AD. However other neurotransmission systems, such as the noradrenergic and cholinergic systems, have for long been known to be impaired in $\mathrm{AD}$ and are also involved in memory and novelty (Bunzeck et al., 2014; Caldenhove et al., 2017). Altogether, this model offers a more realistic view of the memory impairment seen in AD, including local effects on brain structures directly involved in memory such as the MTL, network effects on brain structures such as the posterior cingulate and medial prefrontal areas (La Joie et al., 2012) and effects due to neurotransmitter systems.

This review indicates that novelty processing is impaired in $\mathrm{AD}$, probably impacting memory from an early stage. We have consequently provided a novel model to explain memory impairment throughout the course of $\mathrm{AD}$ disease. We suggest that a better understanding of novelty impairment in $\mathrm{AD}$ is a critical step towards targeted rehabilitation and pharmaceutical programs. 


\section{Acknowledgements}

This work is part of the Knovelty consortium to which the authors belong.

Funding: This work was supported by Wallonie-Bruxelles International (CB, ED), the Fonds de la Recherche Scientifique F.R.S.-FNRS (CB), the Ministère Français des Affaires Étrangères et Européennes (EB, CB, ED), the Ministère de l'Enseignement supérieur et de la recherche as part of Partenariats Hubert Curien (EB, CB, ED), a grant from Fonds Spéciaux pour la Recherche of the Liège University $(\mathrm{CB})$ and a France Alzheimer grant $(\mathrm{EB}, \mathrm{CM})$. 
Declarations of interest

None 


\section{References}

Aberg, C, Nilsson, LG. Facilitation of source discrimination in the novelty effect. Scand. J. Psychol. 2001;42(4):349-357.

Aberg, CS, Nilsson, LG. A strict response criterion yields a mirror effect in the novelty paradigm. Scand. J. Psychol. 2003;44(5):425-432.

Albert, MS, DeKosky, ST, Dickson, D, Dubois, B, Feldman, HH, Fox, NC, Gamst, A, Holtzman, DM, Jagust, WJ, Petersen, RC, Snyder, PJ, Carrillo, MC, Thies, B, Phelps, CH. The diagnosis of mild cognitive impairment due to Alzheimer's disease: recommendations from the National Institute on Aging-Alzheimer's Association workgroups on diagnostic guidelines for Alzheimer's disease. Alzheimers Dement 2011;7(3):270-279.

Ambree, O, Richter, H, Sachser, N, Lewejohann, L, Dere, E, de Souza Silva, MA, Herring, A, Keyvani, K, Paulus, W, Schabitz, WR. Levodopa ameliorates learning and memory deficits in a murine model of Alzheimer's disease. Neurobiol. Aging 2009;30(8):1192-1204.

Badre, D, Wagner, AD. Semantic retrieval, mnemonic control, and prefrontal cortex. Behav. Cogn. Neurosci. Rev. 2002;1(3):206-218.

Barbeau, EJ, Chauvel, P, Moulin, CJ, Regis, J, Liegeois-Chauvel, C. Hippocampus duality: Memory and novelty detection are subserved by distinct mechanisms. Hippocampus 2017;27(4):405-416.

Barbeau, EJ, Didic, M, Felician, O, Tramoni, E, Guedj, E, Ceccaldi, M, Poncet, M. Pure progressive amnesia: An atypical amnestic syndrome? Cogn. Neuropsychol. 2006;23(8):12301247. 
Barbeau, EJ, Didic, M, Joubert, S, Guedj, E, Koric, L, Felician, O, Ranjeva, JP, Cozzone, P, Ceccaldi, M. Extent and neural basis of semantic memory impairment in mild cognitive impairment. J. Alzheimers Dis. 2012;28(4):823-837.

Bastin, C, Bahri, MA, Miévis, F, Lemaire, C, Collette, F, Genon, S, Simon, J, Guillaume, B, Diana, RA, Yonelinas, AP, Salmon, E. Associative memory and its cerebral correlates in Alzheimer's disease: Evidence for distinct deficits of relational and conjunctive memory. Neuropsychologia 2014;63:99-106.

Bastin, C, Kerrouche, N, Lekeu, F, Adam, S, Guillaume, B, Lemaire, C, Aerts, J, d'Ydewalle, G, Collette, F, Salmon, E. Controlled memory processes in questionable Alzheimer's disease: A view from neuroimaging research. J. Alzheimers Dis. 2010;20:547560.

Bastin, C, Van der Linden, M, Lekeu, F, Andres, P, Salmon, E. Variability in the impairment of recognition memory in patients with frontal lobe lesions. Cortex 2006;42(7):983-994.

Bayley, PJ, Salmon, DP, Bondi, MW, Bui, BK, Olichney, J, Delis, DC, Thomas, RG, Thal, LJ. Comparison of the serial position effect in very mild Alzheimer's disease, mild Alzheimer's disease, and amnesia associated with electroconvulsive therapy. J. Int. Neuropsychol. Soc. 2000;6(3):290-298.

Belleville, S, Menard, MC, Lepage, E. Impact of novelty and type of material on recognition in healthy older adults and persons with mild cognitive impairment. Neuropsychologia 2011;49(10):2856-2865. 
Besson, G, Ceccaldi, M, Tramoni, E, Felician, O, Didic, M, Barbeau, EJ. Fast, but not slow, familiarity is preserved in patients with amnestic Mild Cognitive Impairment. Cortex 2015;65:36-49.

Blackford, JU, Buckholtz, JW, Avery, SN, Zald, DH. A unique role for the human amygdala in novelty detection. Neuroimage 2010;50(3):1188-1193.

Blin, O, Masson, G, Azulay, JP, Fondarai, J, Serratrice, G. Apomorphine-induced blinking and yawning in healthy volunteers. Br. J. Clin. Pharmacol. 1990;30(5):769-773.

Braak, H, Braak, E. Staging of Alzheimer's disease-related neurofibrillary changes. Neurobiol. Aging 1995;16(3):271-284.

Braak, H, Thal, DR, Ghebremedhin, E, Del Tredici, K. Stages of the pathologic process in Alzheimer disease: age categories from 1 to 100 years. J. Neuropathol. Exp. Neurol. 2011;70(11):960-969.

Brankack, J, Buzsaki, G. Hippocampal responses evoked by tooth pulp and acoustic stimulation: depth profiles and effect of behavior. Brain Res. 1986;378(2):303-314.

Brown, MW, Bashir, ZI. Evidence concerning how neurons of the perirhinal cortex may effect familiarity discrimination. Phil.Trans.R.Soc.Lond.B 2002;357:1083-1095.

Brueggen, K, Kasper, E, Dyrba, M, Bruno, D, Pomara, N, Ewers, M, Duering, M, Burger, K, Teipel, SJ. The Primacy Effect in Amnestic Mild Cognitive Impairment: Associations with Hippocampal Functional Connectivity. Front. Aging Neurosci. 2016;8:244.

Budson, AE, Michalska, KJ, Sullivan, AL, Rentz, DM, Daffner, KR, Schacter, DL. False recognition in Alzheimer disease: evidence from categorized pictures. Cogn. Behav. Neurol. 2003;16(1):16-27. 
Bunzeck, N, Duzel, E. Absolute coding of stimulus novelty in the human substantia nigra/VTA. Neuron 2006;51(3):369-379.

Bunzeck, N, Guitart-Masip, M, Dolan, RJ, Duzel, E. Pharmacological dissociation of novelty responses in the human brain. Cereb. Cortex 2014;24(5):1351-1360.

Caldenhove, S, Borghans, LGJM, Blokland, A, Sambeth, A. Role of acetylcholine and serotonin in novelty processing using an oddball paradigm. Behav. Brain Res. 2017;331:199204.

Chau, SA, Herrmann, N, Eizenman, M, Chung, J, Lanctot, KL. Exploring Visual Selective Attention towards Novel Stimuli in Alzheimer's Disease Patients. Dement Geriatr Cogn Dis Extra 2015;5(3):492-502.

Chau, SA, Herrmann, N, Sherman, C, Chung, J, Eizenman, M, Kiss, A, Lanctot, KL. Visual Selective Attention Toward Novel Stimuli Predicts Cognitive Decline in Alzheimer's Disease Patients. J. Alzheimers Dis. 2017;55(4):1339-1349.

Cloninger, CR, Przybeck, TR, Svrakic, DM. The Tridimensional Personality Questionnaire: U.S. Normative Data. Psychol. Rep. 1991;69(3):1047-1057.

Corbetta, M, Shulman, GL. Control of goal-directed and stimulus-driven attention in the brain. Nature Reviews : Neuroscience 2002;3:201-215.

Costa, PT, McCrae, RR, 1992. Revised NEO Personality Inventory (NEO-PI-R) and NEO Five-Factor Inventory (NEO-FFI) professional manual. Psychological Assessment Resources, Odessa, FL.

Crottaz-Herbette, S, Lau, KM, Glover, GH, Menon, V. Hippocampal involvement in detection of deviant auditory and visual stimuli. Hippocampus 2005;15(1):132-139. 
Crutcher, MD, Calhoun-Haney, R, Manzanares, CM, Lah, JJ, Levey, AI, Zola, SM. Eye tracking during a visual paired comparison task as a predictor of early dementia. Am. J. Alzheimers Dis. Other Demen. 2009;24(3):258-266.

Cunha, C, Guerreiro, M, de Mendonca, A, Oliveira, PE, Santana, I. Serial position effects in Alzheimer's disease, mild cognitive impairment, and normal aging: predictive value for conversion to dementia. J. Clin. Exp. Neuropsychol. 2012;34(8):841-852.

Daffner, KR, Chong, H, Riis, J, Rentz, DM, Wolk, DA, Budson, AE, Holcomb, PJ. Cognitive status impacts age-related changes in attention to novel and target events in normal adults. Neuropsychology 2007;21(3):291-300.

Daffner, KR, Mesulam, MM, Cohen, LG, Scinto, LF. Mechanisms underlying diminished novelty-seeking behavior in patients with probable Alzheimer's disease. Neuropsychiatry. Neuropsychol. Behav. Neurol. 1999;12(1):58-66.

Daffner, KR, Mesulam, MM, Holcomb, PJ, Calvo, V, Acar, D, Chabrerie, A, Kikinis, R, Jolesz, FA, Rentz, DM, Scinto, LF. Disruption of attention to novel events after frontal lobe injury in humans. J. Neurol. Neurosurg. Psychiatry 2000a;68(1):18-24.

Daffner, KR, Mesulam, MM, Scinto, LF, Acar, D, Calvo, V, Faust, R, Chabrerie, A, Kennedy, B, Holcomb, P. The central role of the prefrontal cortex in directing attention to novel events. Brain 2000b;123 ( Pt 5):927-939.

Daffner, KR, Rentz, DM, Scinto, LF, Faust, R, Budson, AE, Holcomb, PJ. Pathophysiology underlying diminished attention to novel events in patients with early AD. Neurology 2001;56(10):1377-1383. 
Daffner, KR, Ryan, KK, Williams, DM, Budson, AE, Rentz, DM, Wolk, DA, Holcomb, PJ. Age-related differences in attention to novelty among cognitively high performing adults. Biol. Psychol. 2006;72(1):67-77.

Daffner, KR, Scinto, LF, Weintraub, S, Guinessey, J, Mesulam, MM. The impact of aging on curiosity as measured by exploratory eye movements. Arch. Neurol. 1994;51(4):368-376.

Daffner, KR, Scinto, LF, Weintraub, S, Guinessey, JE, Mesulam, MM. Diminished curiosity in patients with probable Alzheimer's disease as measured by exploratory eye movements. Neurology 1992;42(2):320-328.

Daselaar, SM, Fleck, MS, Cabeza, R. Triple dissociation in the medial temporal lobes: recollection, familiarity, and novelty. J. Neurophysiol. 2006;96(4):1902-1911.

Davelaar, EJ. A Novelty-Induced Change in Episodic (NICE) Context Account of Primacy Effects in Free Recall. Psychology 2013;04(09):695-703.

de Chastelaine, M, Mattson, JT, Wang, TH, Donley, BE, Rugg, MD. Independent contributions of fMRI familiarity and novelty effects to recognition memory and their stability across the adult lifespan. Neuroimage 2017;156:340-351.

Delhaye, E, Bastin, C, Moulin, CJA, Besson, G, Barbeau, EJ. Bridging novelty and familiarity-based recognition memory: A matter of timing. Visual Cognition 2017;25(910):949-955.

Dickerson, BC, Salat, DH, Greve, DN, Chua, EF, Rand-Giovannetti, E, Rentz, DM, Bertram, L, Mullin, K, Tanzi, RE, Blacker, D, Albert, MS, Sperling, RA. Increased hippocampal activation in mild cognitive impairment compared to normal aging and AD. Neurology 2005;65:404-411. 
Didic, M, Barbeau, EJ, Felician, O, Tramoni, E, Guedj, E, Poncet, M, Ceccaldi, M. Which memory system is impaired first in Alzheimer's disease? J. Alzheimers Dis. 2011;27(1):11-22.

Downar, J, Crawley, AP, Mikulis, DJ, Davis, KD. A multimodal cortical network for the detection of changes in the sensory environment. Nat. Neurosci. 2000;3(3):277-283.

Dubois, B, Feldman, HH, Jacova, C, Cummings, JL, Dekosky, ST, Barberger-Gateau, P, Delacourte, A, Frisoni, G, Fox, NC, Galasko, D, Gauthier, S, Hampel, H, Jicha, GA, Meguro, K, O'Brien, J, Pasquier, F, Robert, P, Rossor, M, Salloway, S, Sarazin, M, de Souza, LC, Stern, Y, Visser, PJ, Scheltens, P. Revising the definition of Alzheimer's disease: a new lexicon. Lancet Neurol. 2010;9(11):1118-1127.

Dubois, B, Feldman, HH, Jacova, C, Hampel, H, Molinuevo, JL, Blennow, K, DeKosky, ST, Gauthier, S, Selkoe, D, Bateman, R, Cappa, S, Crutch, S, Engelborghs, S, Frisoni, GB, Fox, NC, Galasko, D, Habert, M-O, Jicha, GA, Nordberg, A, Pasquier, F, Rabinovici, G, Robert, P, Rowe, C, Salloway, S, Sarazin, M, Epelbaum, S, de Souza, LC, Vellas, B, Visser, PJ, Schneider, L, Stern, Y, Scheltens, P, Cummings, JL. Advancing research diagnostic criteria for Alzheimer's disease: the IWG-2 criteria. The Lancet Neurology 2014;13(6):614-629.

Duzel, E, Bunzeck, N, Guitart-Masip, M, Duzel, S. NOvelty-related motivation of anticipation and exploration by dopamine (NOMAD): implications for healthy aging. Neurosci. Biobehav. Rev. 2010;34(5):660-669.

Fabiani, M, Friedman, D. Changes in brain activity patterns in aging: The novelty oddball. Psychophysiology 1995;32(6):579-594.

Fenker, DB, Frey, JU, Schuetze, H, Heipertz, D, Heinze, HJ, Duzel, E. Novel scenes improve recollection and recall of words. J. Cogn. Neurosci. 2008;20(7):1250-1265. 
Fernandez, G, Tendolkar, I. The rhinal cortex: 'gatekeeper' of the declarative memory system. Trends Cogn Sci 2006;10(8):358-362.

Fleischman, DA. Repetition priming in aging and Alzheimer's disease: an integrative review and future directions. Cortex 2007;43(7):889-897.

Folstein, MF, Folstein, SE, McHugh, PR. "Mini-mental state": A practical method for grading the cognitive state of patients for the clinician. J. Psychiatr. Res. 1975;12(3):189-198.

Gallo, DA, Sullivan, AL, Daffner, KR, Schacter, DL, Budson, AE. Associative recognition in Alzheimer's disease: Evidence for impaired recall-to-reject. Neuropsychology 2004;18(3):556-563.

Genon, S, Collette, F, Feyers, D, Phillips, C, Salmon, E, Bastin, C. Item familiarity and controlled associative retrieval in Alzheimer's disease: An fMRI study. Cortex 2013;49:15661584.

Genon, S, Collette, F, Moulin, CJA, Lekeu, F, Bahri, MA, Salmon, E, Bastin, C. Verbal learning in Alzheimer's disease and Mild Cognitive Impairment: Fine grained acquisition and consolidation performance and neural correlates. Neurobiol. Aging 2012;34:361-373.

Golby, A, Silverberg, G, Race, E, Gabrieli, S, O'Shea, JO, Knierim, K, Stebbins, G, Gabrieli, J. Memory encoding in Alzheimer's disease: An fMRI study of explicit and implicit memory. Brain 2005;128:773-787.

Grill-Spector, K, Henson, R, Martin, A. Repetition and the brain: neural models of stimulus-specific effects. Trends Cogn Sci 2006;10(1):14-23.

Guzmán-Ramos, K, Moreno-Castilla, P, Castro-Cruz, M, McGaugh, JL, Martínez-Coria, H, LaFerla, FM, Bermúdez-Rattoni, F. Restoration of dopamine release deficits during object 
recognition memory acquisition attenuates cognitive impairment in a triple transgenic mice model of Alzheimer's disease. Learn. Mem. 2012;19(10):453-460.

Habib, R, McIntosh, AR, Wheeler, MA, Tulving, E. Memory encoding and hippocampally-based novelty/familiarity discrimination networks. Neuropsychologia $2003 ; 41: 271-279$.

Halgren, E, Marinkovic, K, Chauvel, P. Generators of the late cognitive potentials in auditory and visual oddball tasks. Electroencephalogr. Clin. Neurophysiol. 1998;106(2):156164.

Halgren, E, Squires, NK, Wilson, CL, Rohrbaugh, JW, Babb, TL, Crandall, PH. Endogenous potentials generated in the human hippocampal formation and amygdala by infrequent events. Science 1980;210(4471):803-805.

Hedges, D, Janis, R, Mickelson, S, Keith, C, Bennett, D, Brown, BL. P300 Amplitude in Alzheimer's Disease: A Meta-Analysis and Meta-Regression. Clin. EEG Neurosci. 2016;47(1):48-55.

Henson, RN, Gagnepain, P. Predictive, interactive multiple memory systems. Hippocampus 2010;20(11):1315-1326.

Horner, Aidan J, Gadian, David G, Fuentemilla, L, Jentschke, S, Vargha-Khadem, F, Duzel, E. A Rapid, Hippocampus-Dependent, Item-Memory Signal that Initiates Context Memory in Humans. Curr. Biol. 2012;22(24):2369-2374.

Howe, AS, Bani-Fatemi, A, De Luca, V. The clinical utility of the auditory P300 latency subcomponent event-related potential in preclinical diagnosis of patients with mild cognitive impairment and Alzheimer's disease. Brain Cogn. 2014;86:64-74. 
Howieson, DB, Mattek, N, Seeyle, AM, Dodge, HH, Wasserman, D, Zitzelberger, T, Jeffrey, K. Serial position effects in mild cognitive impairment. J. Clin. Exp. Neuropsychol. 2011;33(3):292-299.

Hunt, RR. The subtlety of distinctiveness: What von Restorff really did. Psychon Bull Rev 1995;2(1):105-112.

Hunt, RR. Precision in Memory Through Distinctive Processing. Curr. Dir. Psychol. Sci. 2013;22(1):10-15.

Jack, CR, Knopman, DS, Jagust, WJ, Petersen, RC, Weiner, MW, Aisen, PS, Shaw, LM, Vemuri, P, Wiste, HJ, Weigand, SD, Lesnick, TG, Pankratz, VS, Donohue, MC, Trojanowski, JQ. Tracking pathophysiological processes in Alzheimer's disease: an updated hypothetical model of dynamic biomarkers. The Lancet Neurology 2013;12(2):207-216.

Kafkas, A, Montaldi, D. Two separate, but interacting, neural systems for familiarity and novelty detection: a dual-route mechanism. Hippocampus 2014;24(5):516-527.

Kafkas, A, Montaldi, D. Striatal and midbrain connectivity with the hippocampus selectively boosts memory for contextual novelty. Hippocampus 2015;25(11):1262-1273.

Kafkas, A, Montaldi, D. How do memory systems detect and respond to novelty? Neurosci. Lett. 2018;680:60-68.

Kaminski, J, Mamelak, AN, Birch, K, Mosher, CP, Tagliati, M, Rutishauser, U. NoveltySensitive Dopaminergic Neurons in the Human Substantia Nigra Predict Success of Declarative Memory Formation. Curr. Biol. 2018;28(9):1333-1343.e1334.

Karson, CN. Spontaneous eye-blink rates and dopaminergic systems. Brain 1983;106 (Pt 3):643-653. 
Keane, MM, Gabrieli, JD, Fennema, AC, Growdon, JH, Corkin, S. Evidence for a dissociation between perceptual and conceptual priming in Alzheimer's disease. Behav. Neurosci. 1991;105(2):326-342.

Kirchhoff, BA, Wagner, AD, Maril, A, Stern, CE. Prefrontal-temporal circuitry for episodic encoding and subsequent memory. J. Neurosci. 2000;20(16):6173-6180.

Kishiyama, MM, Yonelinas, AP, Lazzara, MM. The von Restorff effect in amnesia: the contribution of the hippocampal system to novelty-related memory enhancements. J. Cogn. Neurosci. 2004;16(1):15-23.

Koch, G, Di Lorenzo, F, Bonni, S, Giacobbe, V, Bozzali, M, Caltagirone, C, Martorana, A. Dopaminergic modulation of cortical plasticity in Alzheimer's disease patients. Neuropsychopharmacology 2014;39(11):2654-2661.

Koen, JD, Yonelinas, AP. The effects of healthy aging, amnestic mild cognitive impairment, and Alzheimer's disease on recollection and familiarity: a meta-analytic review. Neuropsychol. Rev. 2014;24(3):332-354.

Kohler, S, Danckert, S, Gati, JS, Menon, RS. Novelty responses to relational and nonrelational information in the hippocampus and the parahippocampal region: a comparison based on event-related fMRI. Hippocampus 2005;15(6):763-774.

Kormi-Nouri, R, Nilsson, LG, Ohta, N. The novelty effect: support for the NoveltyEncoding Hypothesis. Scand. J. Psychol. 2005;46(2):133-143.

Kumaran, D, Maguire, EA. An unexpected sequence of events: mismatch detection in the human hippocampus. PLoS Biol. 2006;4(12):e424. 
Kumaran, D, Maguire, EA. Match mismatch processes underlie human hippocampal responses to associative novelty. J. Neurosci. 2007a;27(32):8517-8524.

Kumaran, D, Maguire, EA. Which computational mechanisms operate in the hippocampus during novelty detection? Hippocampus 2007b;17(9):735-748.

Kumaran, D, Maguire, EA. Novelty signals: a window into hippocampal information processing. Trends Cogn Sci 2009;13(2):47-54.

La Joie, R, Perrotin, A, Barre, L, Hommet, C, Mezenge, F, Ibazizene, M, Camus, V, Abbas, A, Landeau, B, Guilloteau, D, de La Sayette, V, Eustache, F, Desgranges, B, Chetelat, G. Region-specific hierarchy between atrophy, hypometabolism, and beta-amyloid (Abeta) load in Alzheimer's disease dementia. J. Neurosci. 2012;32(46):16265-16273.

Lee, MS, Lee, SH, Moon, EO, Moon, YJ, Kim, S, Kim, SH, Jung, IK. Neuropsychological correlates of the P300 in patients with Alzheimer's disease. Prog. Neuropsychopharmacol. Biol. Psychiatry 2013;40:62-69.

Lekeu, F, Van der Linden, M, Degueldre, C, Lemaire, C, Luxen, A, Moonen, G, Salmon, E. Effects of Alzheimer's disease on the recognition of novel versus familiar words: Neuropsychological and clinico-metabolic data. Neuropsychology 2003;17(1):143-154.

Lisman, J, Grace, AA. The hippocampal-VTA loop: controlling the entry of information into long-term memory. Neuron 2005;46(5):703-713.

Lisman, J, Grace, AA, Duzel, E. A neoHebbian framework for episodic memory; role of dopamine-dependent late LTP. Trends Neurosci. 2011;34(10):536-547.

Litman, J. Curiosity and the pleasures of learning: Wanting and liking new information. Cognition and Emotion 2005;19(6):793-814. 
Martorana, A, Koch, G. "Is dopamine involved in Alzheimer's disease?". Front. Aging Neurosci. 2014;6:252.

McCarthy, G, Wood, CC, Williamson, PD, Spencer, DD. Task-dependent field potentials in human hippocampal formation. J. Neurosci. 1989;9(12):4253-4268.

McKoon, G, Ratcliff, G. Priming in episodic and semantic memory. Journal of Verbal Learning and Verbal Behavior 1979;18:463-480.

Miller, SL, Fenstermacher, E, Bates, J, Blacker, D, Sperling, RA, Dickerson, BC. Hippocampal activation in adults with mild cognitive impairment predicts subsequent cognitive decline. Journal of Neurology, Neurosurgery, and Psychiatry 2008;79(6):630-635.

Molitor, RJ, Ko, PC, Ally, BA. Eye movements in Alzheimer's disease. J. Alzheimers Dis. $2015 ; 44(1): 1-12$.

Moser, A, Kompf, D, Olschinka, J. Eye movement dysfunction in dementia of the Alzheimer type. Dementia 1995;6(5):264-268.

Moulin, CJA, Perfect, TJ, Jones, RW. Evidence for intact memory monitoring in Alzheimer's disease : Metamemory sensitivity at encoding. Neuropsychologia 2000;38:12421250.

Munoz, M, Chadwick, M, Perez-Hernandez, E, Vargha-Khadem, F, Mishkin, M. Novelty preference in patients with developmental amnesia. Hippocampus 2011;21(12):1268-1276.

Naber, M, Frassle, S, Rutishauser, U, Einhauser, W. Pupil size signals novelty and predicts later retrieval success for declarative memories of natural scenes. J Vis 2013;13(2):11. 
Nairne, JS, 2006. Modelling distinctiveness: Implications for general memory theory, in: Hunt, R.R., Worthen, J.B. (Eds.), Distinctiveness and memory. University Press, Oxford, pp. $27-46$.

Nestor, PJ, Fryer, TD, Hodges, JR. Declarative memory impairments in Alzheimer's disease and semantic dementia. Neuroimage 2006;30(3):1010-1020.

Nobili, A, Latagliata, EC, Viscomi, MT, Cavallucci, V, Cutuli, D, Giacovazzo, G, Krashia, P, Rizzo, FR, Marino, R, Federici, M, De Bartolo, P, Aversa, D, Dell'Acqua, MC, Cordella, A, Sancandi, M, Keller, F, Petrosini, L, Puglisi-Allegra, S, Mercuri, NB, Coccurello, R, Berretta, N, D'Amelio, M. Dopamine neuronal loss contributes to memory and reward dysfunction in a model of Alzheimer's disease. Nat Commun 2017;8:14727.

Nyberg, L. Any novelty in hippocampal formation and memory? Curr. Opin. Neurol. 2005;18(4):424-428.

O'Brien, JL, O'Keefe, KM, LaViolette, PS, DeLuca, AN, Blacker, D, Dickerson, BC, Sperling, RA. Longitudinal fMRI in elderly reveals loss of hippocampal activation with clinical decline. Neurology 2010;74(24):1969-1976.

Ober, BA, Shenaut, GK. Repetition priming of words and nonwords in Alzheimer's disease and normal aging. Neuropsychology 2014;28(6):973-983.

Ogrocki, PK, Hills, AC, Strauss, ME. Visual exploration of facial emotion by healthy older adults and patients with Alzheimer disease. Neuropsychiatry. Neuropsychol. Behav. Neurol. 2000;13(4):271-278.

Otmakhova, N, Duzel, E, Deutch, AY, Lisman, J, 2013. The Hippocampal-VTA Loop: The Role of Novelty and Motivation in Controlling the Entry of Information into Long-Term 
Memory, in: Baldassarre, G., Mirolli, M. (Eds.), Intrinsically Motivated Learning in Natural and Artificial Systems. Springer-Verlag, Berlin Heidelberg, pp. 235-254.

Pascalis, O, Hunkin, NM, Holdstock, JS, Isaac, CL, Mayes, AR. Visual paired comparison performance is impaired in a patient with selective hippocampal lesions and relatively intact item recognition. Neuropsychologia 2004;42(10):1293-1300.

Pihlajamaki, M, O'Keefe, K, O'Brien, J, Blacker, D, Sperling, RA. Failure of repetition suppression and memory encoding in aging and Alzheimer's disease. Brain Imaging Behav 2011;5(1):36-44.

Polich, J. Updating P300: an integrative theory of P3a and P3b. Clin. Neurophysiol. 2007;118(10):2128-2148.

Poppenk, J, Kohler, S, Moscovitch, M. Revisiting the novelty effect: when familiarity, not novelty, enhances memory. J. Exp. Psychol. Learn. Mem. Cogn. 2010a;36(5):1321-1330.

Poppenk, J, McIntosh, AR, Craik, FI, Moscovitch, M. Past experience modulates the neural mechanisms of episodic memory formation. J. Neurosci. 2010b;30(13):4707-4716.

Poppenk, J, Walia, G, McIntosh, AR, Joanisse, MF, Klein, D, Kohler, S. Why is the meaning of a sentence better remembered than its form? An fMRI study on the role of noveltyencoding processes. Hippocampus 2008;18(9):909-918.

Putcha, D, Brickhouse, M, O'Keefe, K, Sullivan, C, Rentz, D, Marshall, G, Dickerson, B, Sperling, R. Hippocampal hyperactivation associated with cortical thinning in Alzheimer's disease signature regions in non-demented elderly adults. J. Neurosci. 2011;31(48):1768017688. 
Ranganath, C, Rainer, G. Neural mechanisms for detecting and remembering novel events. Nat. Rev. Neurosci. 2003;4(3):193-202.

Ratcliff, G. A theory of memory retrieval. Psychol. Rev. 1978;85(2):59-108.

Reggev, N, Bein, O, Maril, A. Distinct Neural Suppression and Encoding Effects for Conceptual Novelty and Familiarity. J. Cogn. Neurosci. 2016;28(10):1455-1470.

Robert, P, Onyike, CU, Leentjens, AF, Dujardin, K, Aalten, P, Starkstein, S, Verhey, FR, Yessavage, J, Clement, JP, Drapier, D, Bayle, F, Benoit, M, Boyer, P, Lorca, PM, Thibaut, F, Gauthier, S, Grossberg, G, Vellas, B, Byrne, J. Proposed diagnostic criteria for apathy in Alzheimer's disease and other neuropsychiatric disorders. Eur. Psychiatry 2009;24(2):98-104.

Robins Wahlin, TB, Byrne, GJ. Personality changes in Alzheimer's disease: a systematic review. Int. J. Geriatr. Psychiatry 2011;26(10):1019-1029.

Rombouts, SA, Barkhof, F, Veltman, DJ, Machielsen, WC, Witter, MP, Bierlaagh, MA, Lazeron, RH, Valk, J, Scheltens, P. Functional MR imaging in Alzheimer's disease during memory encoding. AJNR Am. J. Neuroradiol. 2000;21(10):1869-1875.

Rutishauser, U, Mamelak, AN, Schuman, EM. Single-trial learning of novel stimuli by individual neurons of the human hippocampus-amygdala complex. Neuron 2006;49(6):805813.

Salat, DH, Kaye, JA, Janowsky, JS. Selective preservation and degeneration within the prefrontal cortex in aging and Alzheimer disease. Arch. Neurol. 2001;58(9):1403-1408.

Schacter, DL, Curran, T, Gallucio, L, Milberg, WP, Bates, JF. False recognition and the right frontal lobe : A case study. Neuropsychologia 1996;34:793-808. 
Schoemaker, D, Gauthier, S, Pruessner, JC. Recollection and familiarity in aging individuals with mild cognitive impairment and Alzheimer's disease: a literature review. Neuropsychol. Rev. 2014;24(3):313-331.

Schomaker, J, Meeter, M. Short- and long-lasting consequences of novelty, deviance and surprise on brain and cognition. Neurosci. Biobehav. Rev. 2015;55:268-279.

Schomaker, J, van Bronkhorst, ML, Meeter, M. Exploring a novel environment improves motivation and promotes recall of words. Front. Psychol. 2014;5:918.

Schott, BH, Sellner, DB, Lauer, CJ, Habib, R, Frey, JU, Guderian, S, Heinze, HJ, Duzel, E. Activation of midbrain structures by associative novelty and the formation of explicit memory in humans. Learn. Mem. 2004;11(4):383-387.

Selkoe, DJ, Hardy, J. The amyloid hypothesis of Alzheimer's disease at 25 years. EMBO Mol. Med. 2016;8(6):595-608.

Sperling, R, Mormino, E, Johnson, K. The evolution of preclinical Alzheimer's disease: implications for prevention trials. Neuron 2014;84(3):608-622.

Sperling, RA, Bates, JF, Chua, EF, Cocchiarella, AJ, Rentz, DM, Rosen, BR, Schacter, DL, Albert, MS. fMRI studies of associative encoding in young and elderly controls and mild Alzheimer's disease. J. Neurol. Neurosurg. Psychiatry 2003;74:44-50.

Stern, CE, Corkin, S, Gonzalez, RG, Guimaraes, AR, Baker, JR, Jennings, PJ, Carr, CA, Sugiura, RM, Vedantham, V, Rosen, BR. The hippocampal formation participates in novel picture encoding : Evidence from functional magnetic resonance imaging. Proc.Natl.Acad.Sci. 1996;93:8660-8665.

Stern, Y. Cognitive reserve. Neuropsychologia 2009;47(10):2015-2028. 
Strange, BA, Dolan, RJ. Adaptive anterior hippocampal responses to oddball stimuli. Hippocampus 2001;11(6):690-698.

Strange, BA, Hurlemann, R, Duggins, A, Heinze, HJ, Dolan, RJ. Dissociating intentional learning from relative novelty responses in the medial temporal lobe. Neuroimage 2005;25(1):51-62.

Sutphen, CL, Jasielec, MS, Shah, AR, Macy, EM, Xiong, C, Vlassenko, AG, Benzinger, TL, Stoops, EE, Vanderstichele, HM, Brix, B, Darby, HD, Vandijck, ML, Ladenson, JH, Morris, JC, Holtzman, DM, Fagan, AM. Longitudinal Cerebrospinal Fluid Biomarker Changes in Preclinical Alzheimer Disease During Middle Age. JAMA Neurol 2015;72(9):1029-1042.

Taylor, JR, Elsworth, JD, Lawrence, MS, Sladek, JR, Jr., Roth, RH, Redmond, DE, Jr. Spontaneous blink rates correlate with dopamine levels in the caudate nucleus of MPTP-treated monkeys. Exp. Neurol. 1999;158(1):214-220.

Thompson-Schill, SL, D'Esposito, M, Aguirre, GK, Farah, MJ. Role of left inferior prefrontal cortex in retrieval of semantic knowledge: A reevaluation. Proc.Natl.Acad.Sci.USA 1997;94:14792-14797.

Troyer, AK, Murphy, KJ, Anderson, ND, Craik, FI, Moscovitch, M, Maione, A, Gao, F. Associative recognition in mild cognitive impairment: relationship to hippocampal volume and apolipoprotein E. Neuropsychologia 2012;50(14):3721-3728.

Tulving, E, Kroll, N. Novelty assessment in the brain and long-term memory encoding. Psychon Bull Rev 1995;2(3):387-390.

Tulving, E, Markowitsch, HJ, Craik, FE, Habib, R, Houle, S. Novelty and familiarity activations in PET studies of memory encoding and retrieval. Cereb. Cortex 1996;6(1):71-79. 
Tulving, E, Rosenbaum, RS, 2006. What do explanations of the distinctiveness effect need to explain?, in: Hunt, R.R., Worthen, J.B. (Eds.), Distinctiveness and Memory. Oxford University Press, New York, NY, pp. 407-423.

Vaidya, CJ, Gabrieli, JD, Monti, LA, Tinklenberg, JR, Yesavage, JA. Dissociation between two forms of conceptual priming in Alzheimer's disease. Neuropsychology 1999;13(4):516-524.

Vallet, GT, Hudon, C, Bier, N, Macoir, J, Versace, R, Simard, M. A SEMantic and EPisodic Memory Test (SEMEP) Developed within the Embodied Cognition Framework: Application to Normal Aging, Alzheimer's Disease and Semantic Dementia. Front. Psychol. 2017;8:1493.

van Kesteren, MT, Ruiter, DJ, Fernandez, G, Henson, RN. How schema and novelty augment memory formation. Trends Neurosci. 2012;35(4):211-219.

Vitali, P, Minati, L, Chiarenza, G, Brugnolo, A, Girtler, N, Nobili, F, De Leo, C, Rosati, P, Rodriguez, G. The Von Restorff effect in ageing and Alzheimer's disease. Neurol. Sci. 2006;27(3):166-172.

Vo, ML, Jacobs, AM, Kuchinke, L, Hofmann, M, Conrad, M, Schacht, A, Hutzler, F. The coupling of emotion and cognition in the eye: introducing the pupil old/new effect. Psychophysiology 2008;45(1):130-140.

Von Restorff, H. Uber die Wirkung von Bereichsbildungen im Spurenfeld [The effects of field formation in the trace field]. Psychol. Forsch. 1933;18:199-234.

Westerberg, C, Mayes, A, Florczak, SM, Chen, Y, Creery, J, Parrish, T, Weintraub, S, Mesulam, MM, Reber, PJ, Paller, KA. Distinct medial temporal contributions to different forms 
of recognition in amnestic mild cognitive impairment and Alzheimer's disease. Neuropsychologia 2013;51(12):2450-2461.

Wittmann, BC, Bunzeck, N, Dolan, RJ, Duzel, E. Anticipation of novelty recruits reward system and hippocampus while promoting recollection. Neuroimage 2007;38(1):194-202.

Wittmann, BC, Schott, BH, Guderian, S, Frey, JU, Heinze, HJ, Duzel, E. Reward-related FMRI activation of dopaminergic midbrain is associated with enhanced hippocampusdependent long-term memory formation. Neuron 2005;45(3):459-467.

Wolk, DA, Dunfee, KL, Dickerson, BC, Aizenstein, HJ, DeKosky, ST. A medial temporal lobe division of labor: insights from memory in aging and early Alzheimer disease. Hippocampus 2011;21(5):461-466.

Wolk, DA, Mancuso, L, Kliot, D, Arnold, SE, Dickerson, BC. Familiarity-based memory as an early cognitive marker of preclinical and prodromal AD. Neuropsychologia 2013;51:1094-1102.

Xiang, JZ, Brown, MW. Differential neuronal encoding of novelty, familiarity and recency in regions of the anterior temporal lobe. Neuropharmacology 1998;37(4-5):657-676.

Yamaguchi, S, Hale, LA, D'Esposito, M, Knight, RT. Rapid prefrontal-hippocampal habituation to novel events. J. Neurosci. 2004;24(23):5356-5363.

Yamazaki, T, Kamijo, K, Kiyuna, T, Takaki, Y, Kuroiwa, Y. Multiple dipole analysis of visual event-related potentials during oddball paradigm with silent counting. Brain Topogr. 2001;13(3):161-168. 
Yeung, LK, Olsen, RK, Bild-Enkin, HEP, D'Angelo, MC, Kacollja, A, McQuiggan, DA, Keshabyan, A, Ryan, JD, Barense, MD. Anterolateral Entorhinal Cortex Volume Predicted by Altered Intra-Item Configural Processing. J. Neurosci. 2017;37(22):5527-5538.

Yeung, LK, Ryan, JD, Cowell, RA, Barense, MD. Recognition memory impairments caused by false recognition of novel objects. J. Exp. Psychol. Gen. 2013;142(4):1384-1397. 
Figure captions

Figure 1. Illustration of the oddball paradigm (left) and of the von Restorff paradigm (right). In this version of the von Restorff paradigm, an item, the isolate, is made distinct using a different colour for the font, leading to a perceptual novelty effect.

Figure 2. Three classes of models of novelty detection relatively to familiarity detection. See text for a detailed description.

Figure 3. ERPs recorded in the hippocampus of epileptic patients undergoing intracerebral recordings in the context of preneurosurgical evaluation (mean ERPs across 5 subjects). The ERP evoked by oddball stimuli to which subjects attended (blue) induce a large response in the hippocampus peaking around 400ms. In contrast, irrelevant, frequent, stimuli (green) presented during the oddball task do not induce any ERP. The same set of stimuli, including oddballs (brown), presented to the subjects while they did not have to pay attention to them do not induce any component, suggesting that the hippocampus is involved in endogenous attention to novel stimuli.

Figure 4. Schematic representation of the hippocampal-VTA loop supporting encoding of novel stimuli (after Lisman \& Grace, 2005)

Figure 5. A novel proposition explaining memory impairment in Alzheimer's disease, taking into account each putative source of impairment: medial temporal lobe lesions due to tau pathology, medial cortical network impairment associated with amyloid pathology, such as the abnormalities robustly observed in the posterior cingulate gyrus in AD and novelty impairment due to both medial temporal lobe and dopaminergic dysfunctions. These various sources of memory impairment could accumulate and explain the severe, and typical, memory impairment seen in AD. It could also explain the variety of memory impairments presentation observed in this disease. 
Table 1. List and definitions of specific terms used in this review article

Term Definition

\begin{tabular}{|c|c|}
\hline Associative novelty & A novel configuration or combination of familiar stimuli \\
\hline Contextual novelty & A familiar stimulus that is unexpected in a given context \\
\hline Distinctiveness & A familiar stimulus that stands out from others in a series \\
\hline Orienting response & $\begin{array}{l}\text { An organism's immediate reaction to changes in the environment, irrespective } \\
\text { of the intensity or the quality of the novel information }\end{array}$ \\
\hline$P 3$ & $\begin{array}{l}\text { An event-related brain potential (ERP) correlate of the evaluation of } \\
\text { contextual novelty }\end{array}$ \\
\hline
\end{tabular}

Priming Facilitated processing when a stimulus is repeated

Primacy effect $\quad$ Enhanced memory for first items in a list

Repetition Decreased neural activity related to the progressive familiarization of a novel

suppression stimulus

Stimulus novelty An unfamiliar stimulus or stimulus that has never been experienced before

Surprise The violation of expectancies or the deviation from explicit prediction. The critical issue is of a deviance from an anticipated event or stimulus, rather than a contextually novel stimulus, such as an unexpected sequence, rather than a novel single stimulus (see Schomaker and Meyer, 2015 for development of this idea). 
Table 2. Main findings on novelty processing in AD and in individuals at risk for AD. VPC:

Visual Paired Comparison.

In $\mathrm{AD}$

In individuals at risk for $\mathrm{AD}$

Stimulus novelty

Decreased viewing time to novel

MCI: Decreased viewing time to novel stimuli (Chau et al., 2015), stimuli in VPC, only if study-test delay of 2 associated with apathy (Daffner et al., 1992, 1999). min (Crutcher et al., 2009)

At risk healthy older: Reduction of fixations to novel items that are similar to studied items, but preserved novelty response to dissimilar novel items (Yeung et al., 2013).

Contextual novelty

Reduced novelty P3 in an oddball task (Daffner et al., 2001).

Novelty-related memory effects

Reduced primacy effect in list MCI: reduced primacy effect predicts recall (Bayley et al., 2000; Cunha et al., 2012). progression to AD (Cunha et al., 2012).

Disappearance of the von Restorff effect with perceptual distinctiveness (Vallet et al., 2017; Vitali et al., 2006)

Diminished, but not abolished, $\quad$ MCI: intact recognition memory for novel benefit of memory for novel over items (Belleville et al., 2011). familiarized items; related to hippocampal integrity (Lekeu et al., 2003) 
Table 3. Outstanding questions remaining to be clarified about AD and novelty processing.

1. What is the pattern of impairment associated with AD across the different types of novelty?

2. Is novelty processing impaired following the same time course as memory in AD? Is it impaired at the prodromal stage of AD? Does it decline at the same rate as familiarity?

3. What is the impact of the dopaminergic neuromodulation on memory in AD?

4. Is there a link between novelty detection and apathy or novelty seeking in AD?

5. Can novelty be used to improve memory in AD? 